\title{
Solvent retention in thin polymer films studied by gas chromatography
}

\author{
J. García-Turiel · B. Jérôme
}

Received: 23 March 2007 / Revised: 28 May 2007 / Accepted: 27 June 2007 / Published online: 6 September 2007

(C) Springer-Verlag 2007

\begin{abstract}
Thin polystyrene films were produced by spin coating from solutions in toluene. The amount of solvent retained in the films after drying for different times was measured using gas chromatography. Whereas for thicker films (thickness $>200 \mathrm{~nm}$ ), the relative amount of solvent in the films is less than a few percent, the proportion of toluene increases significantly in thinner films. The thickness dependence of the mass of retained solvent shows that the solvent is mainly retained at the polymer-substrate interface. The solvent desorption rate exhibits no variation on the film thickness.
\end{abstract}

Keywords Polymer films • Solvent desorption • Gas chromatography $\cdot$ Polystyrene

\section{Introduction}

Although most mechanical applications of polymers take advantage of their bulk properties, there are

J. García-Turiel · B. Jérôme ( $\varangle)$

van 't Hoff Institute for Molecular Sciences,

University of Amsterdam, Nieuwe Achtergracht 166,

1018 WV Amsterdam, The Netherlands

e-mail: jerome@science.uva.nl

B. Jérôme

Laboratoire PMCN, CNRS, UMR 5586, Université de Lyon, 69000 Lyon, France numerous technologies based on ultra thin and thin polymers. For example, they are used as resists and interlayer dielectrics in microelectronics fabrication, alignment layers in liquid crystal displays, and lubricants in magnetic information storage devices. In these applications, the polymer chain orientation and state of organization play an important role in determining the final properties of the films [1].

Thin films are usually fabricated by spin-casting. In this coating procedure, a polymer solution is first deposited on the substrate, and the substrate is then accelerated rapidly. Owing to the centrifugal force, a film of the solution is formed, and the excess is ejected off the edge of the substrate. The film continues to thin slowly until disjoining pressure effects causing the film to reach an equilibrium thickness or until it turns solid-like due to a dramatic rise in viscosity resulting from the solvent evaporation. The final thinning of the film is then due solely to solvent evaporation [2]. Most of the solvent evaporates during the last step of the spin-coating, but it is known that some solvent is still present in the films at the end of the spin-coating $[1,3,4]$ and that the polymer chains are quenched in a nonequilibrated state [5-8]. Spin-coated films are therefore generally annealed above the glass transition temperature of the polymer to dry the films and let the polymer relax to equilibrium. Whereas solvent loss during this drying step (with respect to the initial solvent content) has been extensively studied [3, 4, 9-15], there is hardly any information available on the absolute amount of solvent left in the films.

There is however a number of reported results suggesting that some solvent is retained in dried films. In 
absorption/desorption experiments of toluene in several methacrylate polymer films, Saby-Dubreuil et al. [16] observed that some of the absorbed toluene remains trapped in the films even after extensive drying. The presence of solvent in films has also been detected through some changes in the film properties [17, 18]. A striking result is the fact that the glass transition temperature $T_{g}$ of annealed stereo-regular poly(methyl methacrylate) films strongly depends on the solvent used for spin-coating them [19]. $T_{g}$ is either larger or smaller than the transition temperature in bulk, depending on the solvent used. This effect was interpreted as arising from different conformations of the polymer chains persisting even after annealing. The presence of solvent retained in the films could be another explanation. Finally, the mechanical adhesion of annealed diblock copolymer films on the supporting substrate was also observed to depend on the solvent used for spin-coating [20], suggesting again a possible presence of solvent retained after drying.

Besides the question of whether and how much solvent is retained, one should wonder where the solvent is located in the films. Some of the results mentioned above suggest that the solvent could be segregated at the polymer/substrate interface $[19,20]$. Water absorbed in films of different polymers has also been shown to be located at the polymer/substrate interface [21-25]. Another relevant question is the dependence of the amount of retained solvent with the film thickness. Indeed, properties of polymer films, such as the glass transition temperature and the molecular dynamics, are known to change as the film thickness decreases below a few $100 \mathrm{~nm}$ [26-29].

We have therefore studied the amount of solvent retained in polystyrene (PS) films spin-coated from a solution in toluene as a function of film thickness in the range of $15-500 \mathrm{~nm}$. The absolute amounts of retained solvent were investigated using gas chromatography (GC), which appears to be a very useful technique to perform residual solvent analysis, even for the minute volumes of our thin films.

In the following section, we present how we prepared the samples and measured the amount of solvent retained after drying. In "Results and discussion," we show our results on the amount of toluene retained in PS films as a function of film thickness and drying time. We discuss the implications of these results, showing that there is a significant proportion of solvent present in ultra-thin films and that this solvent is mainly retained at the interface with the substrate. We also find that the desorption rate is independent of film thickness.

\section{Experimental section}

\section{Sample preparation}

PS films were prepared by spin-coating from solutions of PS in toluene. Standard atactic PS $\left(M_{w}=178 \mathrm{kDa}\right.$, $\mathrm{D}$ (polydispersity) $=1.03, T_{g}=100^{\circ} \mathrm{C}$, Polymer Standards Service-USA) was used to prepare several PS solutions in toluene (Rathburn Chemicals, $\rho=0.867 \mathrm{~g} / \mathrm{cm}^{3}$, $T_{b}=110.6^{\circ} \mathrm{C}$ ). Toluene was chosen as solvent, as it is one of the most commonly used solvents for the spincoating of PS films.

The films were spin-cast on fused quartz substrates. The substrates were first cleaned in an ultrasound bath, successively with acetone and ethanol, and then dried. To oxidize any impurities still present, the substrates were placed in chromosulphuric acid for at least $12 \mathrm{~h}$, rinsed with double distilled water, dried in an oven at $120^{\circ} \mathrm{C}$ for at least $2 \mathrm{~h}$, and cooled in air until room temperature is reached.

To make films, toluene solutions of PS were filtered and spin-cast at 2,500 rpm for $30 \mathrm{~s}$. The concentration of PS in the solution determines the thickness of the films obtained after spin-coating (which varied between 15 and $500 \mathrm{~nm}$ ), as given by established master curves [30]. The agreement between the thickness of our films and the prediction of the master curves, as well as the uniformity of the films and the absence of defects, was checked by imaging with an atomic force microscope. The films were prepared at room temperature. Spun films were placed in a flow of dry nitrogen, in a chamber with a temperature regulated at $115^{\circ} \mathrm{C}\left(15^{\circ} \mathrm{C}\right.$ above the glass transition temperature of the polymer) for further drying and annealing, and then cooled down at room temperature. The films were dried for different times, ranging from $10 \mathrm{~min}$ to $6 \mathrm{~h}$, to observe the kinetics of the desorption process.

\section{Measurements techniques}

To determine the amount of toluene retained in the films, we dissolved the annealed films with a good solvent (cyclohexanone) for both PS and toluene. The composition of the obtained mixture was then determined with GC. This technique has been already used to perform residual solvent analysis with bulk systems $[31,32]$. The measurements were performed with a Carlo Erba GC 6000 Vega Series gas chromatographer, with a flame ionization detector coupled to a HewlettPackard HP3394A integrator. The injection temperature and the temperature of the column were $200^{\circ} \mathrm{C}$; the temperature at the detector was $230^{\circ} \mathrm{C}$. 
Because the dependence of the signal given by the detector on the toluene quantity is not known, a calibration curve was made of the column response versus toluene concentration using solutions of toluene in cyclohexanone, with known concentrations in the range of $0.05-10 \mu \mathrm{l} / \mathrm{ml}$. A fixed amount of acetonitril was also added as a reference to be able to correct for the differences in the quantities injected into the column of the gas chromatographer. The amount of toluene in the films was expected to be very small. To avoid systematic errors due to uncertainties on the base line of the detector, we dissolved the films (which have a volume varying between 6 and $200 \mathrm{nl}$ ) with $50 \mu \mathrm{l}$ of a toluene-cyclohexanone-acetonitrile solution with a known concentration of toluene. This ternary solution, called working solution, was beforehand analyzed with $\mathrm{GC}$ to use its toluene response as a reference. Then $2 \mu \mathrm{l}$ of the solution resulting from the dissolution of the film was injected in the GC to determine the total concentration of toluene. This concentration had two contributions: (1) the toluene present in the working solution and (2) the toluene present in the dissolved film (which was always at least $10 \%$ of the first contribution). The difference between this last concentration and the concentration in the working solution gives then the amount of toluene present in the film. To obtain good statistics, the analysis of a given solution with GC was repeated three times, and for each film, parameters (thickness and drying time), about four films, were prepared and analyzed. The error bars given in the results show the standard deviation of the measurements.

With this measurement method, we reach detection limits of $10^{-2} \mu \mathrm{g} / \mu \mathrm{l}$ of toluene from the film in the working solution, which corresponds to a total mass of toluene in the films of $0.5 \mu \mathrm{g}$. We have checked the amounts of toluene measured with this method in the case of clean bare substrates (without any film) and bare substrates after spin-coating with pure toluene. The measured amounts of toluene were then zero within the measurement errors.

\section{Results and discussion}

From the GC measurements, we have obtained absolute values of the amount of toluene found inside the polymer films. We describe first the dependence of this amount on the film thickness (in the range 15-500 $\mathrm{nm}$ ), after a drying time of $6 \mathrm{~h}$, and in a second part the desorption kinetics.
Thickness dependence

The mass of toluene found in films is shown in Fig. 1a as a function of film thickness, for a drying time of $6 \mathrm{~h}$ at $115^{\circ} \mathrm{C}$, which is $15^{\circ} \mathrm{C}$ above the glass transition temperature of the polymer. Note that all the films have the same area.

The results can also be translated in terms of the relative amount of solvent retained:

$$
M_{r}=\frac{M_{T}}{M_{T}+M_{P}}
$$

where $M_{T}$ stands for the absolute amount of toluene retained in the film and $M_{P}$ stands for the mass of polymer. $M_{P}$ is defined as:

$M_{P}=\rho_{P} h_{P} A$

where $\rho_{P}$ is the density of the pure polymer, $h_{P}$ is the thickness of a film of pure polymer with mass $M_{P}$, and $A$ is the area of the substrate. The density $\rho_{P}$ of the polymer can, in a very good approximation, be taken as its bulk value $\left(\rho_{P}=1,050 \mathrm{~kg} \mathrm{~m}^{-3}\right)$. It is still a matter of debate whether or not the density of a polymer in an ultra-thin film is different from its density in bulk. For PS, most results agree, however, on the fact that the
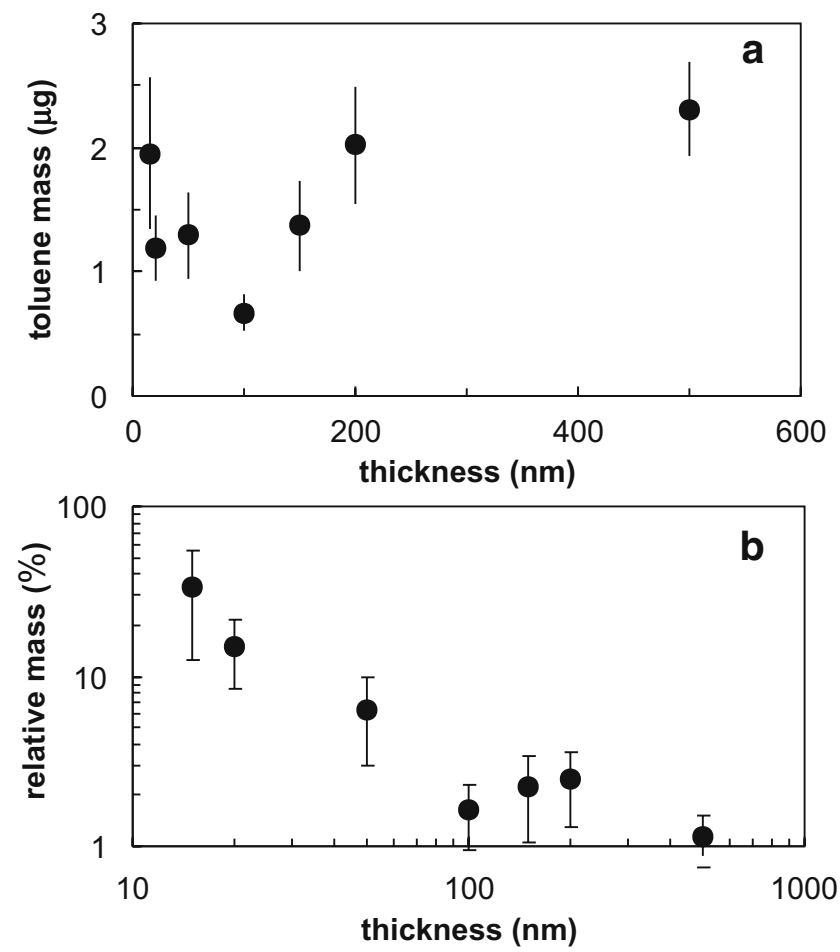

Fig. 1 a Mass $M_{T}$ of toluene retained in films versus film thickness $h$. The annealing temperature is $115^{\circ} \mathrm{C}$ and the annealing time $6 \mathrm{~h}$. b Relative amount $M_{r}$ of toluene retained versus film thickness $h$, calculated from the data in (a) 
polymer density in annealed films thicker than $10 \mathrm{~nm}$ is the same as in bulk [33, 34], and the density at the interface with air and with a supporting substrate differs from the bulk density over distances of at most a few nanometers [35-38].

The equivalent thickness $h_{P}$ of pure polymer in the film can be obtained by subtracting from the film thickness $h$ the thickness $h_{T}$ of a layer of pure toluene of mass $M_{T}$ :

$h_{P}=h-h_{T}=h-M_{T} / \rho_{T} A$

where $\rho_{T}$ is the density of toluene.

The results for the relative amounts $M_{r}$ (Fig. 1b) show a significant increase as the film thickness decreases below $100 \mathrm{~nm}$. For the thinnest films measured, the relative amount of toluene retained goes up to $35 \%$. These ultra-thin samples were also observed under the optical microscope to look for a possible dewetting or breaking of the film, but no sign of it was found. This is consistent with reports in the literature that PS films with thicknesses above $2 \mathrm{~nm}$ are continuous [39, 40]. For film thicknesses above $200 \mathrm{~nm}$, the relative amounts of solvent found in the films are of the order of a few percent or less.

The absolute amount of toluene retained in PS films has only a small dependence on the film thickness, which indicates that the solvent must be mainly located at the interfaces of the film. Another evidence for this segregation at interfaces is the expected glass transition temperature $T_{g}$ of the films if the amount of toluene we find in the films was uniformly distributed in the films. For bulk PS, the dependence of $T_{g}$ on the concentration of toluene absorbed in the polymer has been reported by Chow [41]. We can calculate what would be the glass transition temperature of the films assuming that the amount of toluene we find is uniformly distributed in the films. The result is plotted in Fig. 2, together with the glass transition temperature measured for supported PS films [26, 27], which are generally prepared by spin-coating from a toluene solution and subsequently dried above the glass transition. The values of $T_{g}$ we find are well below the measured values, which agrees with our earlier conclusion that the toluene is concentrated at the interfaces.

It is most likely that the solvent is mainly located at the interface with the substrate rather than at the interface with air, as it would otherwise evaporate. As toluene is a good solvent for PS, there cannot be a sharp interface between the two, and full segregation is improbable. One should rather expect a significant increase of the toluene concentration at the interface with

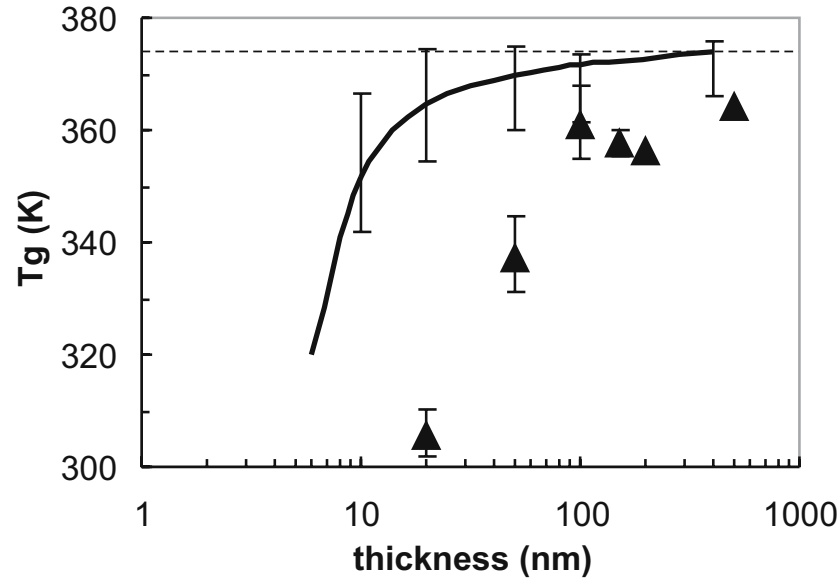

Fig. 2 Glass transition temperature $T_{g}$ of supported PS films. Full line data taken from Forrest et al. [26, 27]; triangles calculated values assuming that the mass $M_{T}$ of toluene is uniformly distributed in the films, using the dependence of $T_{g}$ on toluene concentration of Chow [41]. The disagreement between the calculated values and the measured values is an additional evidence that the toluene is concentrated at the interfaces. The dashed line is the bulk $T_{g}$ value

the substrate, which decreases over a certain length scale.

Segregation of solvent at the polymer/substrate interface of supported polymer films has already been observed in absorption experiments in which the films are put in the presence of the solvent vapor [21-25, 42]. It was attributed to the preferential interaction of the solvent with the substrate [25]. On the contrary, when this interaction is unfavorable, as in the case of water in the presence of a hydrophobic surface, a depletion of the solvent was observed close to the substrate [25].

To estimate the role of the molecule/substrate interactions in our case, we can evaluate the interfacial energies $\gamma_{G T}$ and $\gamma_{G P}$ of a glass/toluene and glass/PS interface, respectively, using the decomposition of interfacial energies in contributions corresponding to different interactions between the adjacent media [43, 44]. The interfacial energy $\gamma_{12}$ between media 1 and 2 can be written in the following form:

$$
\begin{aligned}
\gamma_{12}= & \left(\sqrt{\gamma_{1}^{\mathrm{LW}}}-\sqrt{\gamma_{2}^{\mathrm{LW}}}\right)^{2} \\
& +2\left(\sqrt{\gamma_{1}^{+} \gamma_{1}^{-}}+\sqrt{\gamma_{2}^{+} \gamma_{2}^{-}}-\sqrt{\gamma_{1}^{+} \gamma_{2}^{-}}-\sqrt{\gamma_{1}^{-} \gamma_{2}^{+}}\right)
\end{aligned}
$$

where $\gamma_{i}^{\mathrm{LW}}$ is the Lifschitz-van der Waals (or dispersive) component of the surface tension of medium $i$, $\gamma_{i}^{+}$is the electron-acceptor (Lewis acid) component, and $\gamma_{i}^{-}$is the electron-donor (Lewis base) component. 
Table 1 Values of the surface tension components (at room temperature) for the materials relevant to our study

\begin{tabular}{llll}
\hline Material & $\begin{array}{l}\gamma^{\mathrm{LW}} \\
\left(\mathrm{mJ} \mathrm{m}^{-2}\right)\end{array}$ & $\begin{array}{l}\gamma^{+} \\
\left(\mathrm{mJ} \mathrm{m}^{-2}\right)\end{array}$ & $\begin{array}{l}\gamma^{-} \\
\left(\mathrm{mJ} \mathrm{m}^{-2}\right)\end{array}$ \\
\hline Glass [47] & 37 & 1 & 45 \\
Toluene [45] & 27 & 0 & 1 \\
Polystyrene [48] & 36 & 0 & 1 \\
\hline
\end{tabular}

The fact that we evaluate $\gamma_{G T}$ and $\gamma_{G P}$ at room temperature instead of $115^{\circ} \mathrm{C}$ is not relevant, as the temperature dependence of the components are is expected to significantly differ for toluene and PS $[49,50]$

Using values of the different components available in the literature (Table 1), we obtain the following interfacial energies: $\gamma_{G T}=12 \mathrm{~mJ} \mathrm{~m}^{-2}, \gamma_{G P}=11 \mathrm{~mJ} \mathrm{~m}^{-2}$. These values are very close to each other, in particular in view of their variation on the method used to determine them. For instance, the interfacial energy of the glass/toluene interface can also be determined from the literature values of the surface tension of toluene $\left(\gamma_{T}=29 \mathrm{~mJ} \mathrm{~m}^{-2}[45,46]\right)$, the contact angle of toluene on glass $\left(\theta=6^{\circ}[46]\right)$, and the surface energy of glass $\left(\gamma_{G}=48 \mathrm{~mJ} \mathrm{~m}^{-2}\right.$ [47]), using Young's relation: $\gamma_{G T}=\gamma_{G}-\gamma_{T} \cos \theta=19 \mathrm{~mJ} \mathrm{~m}^{-2}$. This shows that the difference between the values of $\gamma_{G T}$ and $\gamma_{G P}$ found above is not significant and energetic considerations cannot explain the preferential location of toluene at the interface with the substrate.

Another factor determining the preferred location of solvent in our system is entropy. The presence of a hard wall reduces the number of configurations accessible to the polymer chains in the vicinity of the wall, reducing the entropy of the system. Concentrating small molecules at this interface decreases this effect and is therefore favorable with respect to a uniform distribution of solvent in the film. This is the same reason why chain ends are segregated at the interfaces of polymers [51-54].

Another interesting feature is the fact that the solvent retention shows a nontrivial behavior for thicknesses below $200 \mathrm{~nm}$ (Fig. 1a). This limit of $200 \mathrm{~nm}$ corresponds well to the thickness below, which the glass transition temperature of supported PS films departs from the bulk glass transition temperature $[26,27]$ (see also Fig. 2). This shows that this limit corresponds to the thickness below, which the behavior of the system departs from that in bulk. In the 'bulk' regime (thickness $>200 \mathrm{~nm}$ ), the absolute amount of solvent retained is independent of film thickness, whereas in the thin-film regime (thickness $<200 \mathrm{~nm}$ ), we find that the amount of solvent retained does depend on film thickness. It is however not clear what this dependence arises from.

Time dependence

We have also followed the amount of solvent retained over a time range from 0 to $6 \mathrm{~h}$ after the spin-coating. We observe a slight but systematic decrease of the mass of toluene in the films (Fig. 3). By fitting the data with a function of the form $M_{0} \exp (-\alpha t)$, we can calculate the desorption rate $\alpha$. For a drying temperature of $115^{\circ} \mathrm{C}$, this rate is in the range $1-5 \times 10^{-5} \mathrm{~s}^{-1}$ for all film thicknesses (in the range $15-500 \mathrm{~nm}$ ), with no clear thickness dependence. We have also performed the same measurements for a drying temperature of $25^{\circ} \mathrm{C}$, and we find an desorption rate in the range $2-5 \times$ $10^{-6} \mathrm{~s}^{-1}$. However, we reach with these measurements the limit of detectable mass differences, and this value should be considered an upper limit.

Our results at $115^{\circ} \mathrm{C}$ suggest that one should anneal the films for at least $16 \mathrm{~h}$ at this temperature to reduce the amount of solvent below the detection limit of $0.5 \mu \mathrm{g}$ per film of our GC technique. The relative amount of solvent retained in the films would then vary from $0.3 \%$ for $500 \mathrm{~nm}$-thick films to $9 \%$ for $15 \mathrm{~nm}$-thick films. To reduce the concentration of toluene in these thinnest films to below $1 \%$, one should anneal them for at least $43 \mathrm{~h}$, but the absolute amounts of toluene present would then be so small that it would be very difficult to measure them.

The fact that the desorption rate is essentially independent of the film thickness is in agreement with results on absorption rates published in the literature. The absorption rate of water vapor in thin films of

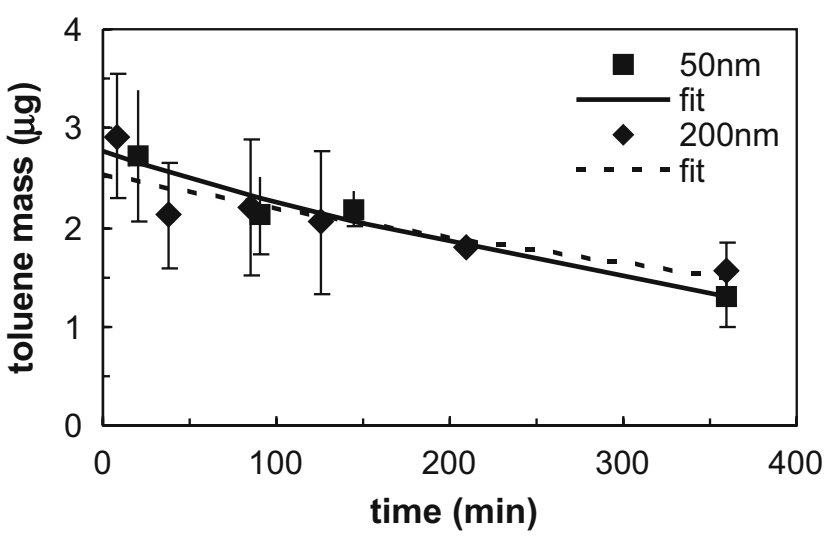

Fig. 3 Mass $M_{T}$ of toluene retained in films versus drying time for 50 and $200 \mathrm{~nm}$-thick films, and the corresponding fits with an exponential decay (full and dashed lines, respectively). The drying temperature is $115^{\circ} \mathrm{C}$ 
poly(vinyl pyrrolidone) [25] and in the polyelectrolyte poly(4-ammonium styrene sulfonic acid) [23] was also found to be independent of film thickness. Note, however, that we work in a rather different regime of solvent concentrations. The above mentioned polymers are hydrophilic, and the concentration of water in the films reaches $50 \%$ when they are put in the presence of saturated water vapor. In our case, the relative amount of solvent present is only a few percent for the thicker films.

To analyze their data, Vogt et al. [23, 25] assumed that the absorption rate was purely determined by the diffusion of the absorbed molecules, after the diffusion models developed for bulk and bulky films [55]. In this case, an absorption rate independent of film thickness means that $D / h^{2}$ (where $D$ is the diffusion coefficient of the absorbed molecules in the film) is independent of film thickness and, therefore, that $D$ varies as $h^{2}[23,25]$. If we make the same assumption, our observation also imply that the diff usion coefficient of toluene in the films varies as $h^{2}$ and, therefore, decreases by several orders of magnitude as the film thickness decreases down to $\sim 10 \mathrm{~nm}$. For the thickest films we have studied $(h=500 \mathrm{~nm})$, the diffusion coefficient estimated from our measurements is $D \approx \alpha h^{2} \approx$ $5 \times 10^{-18} \mathrm{~m}^{2} \mathrm{~s}^{-1}$, which can be considered as a lower limit for the bulk diffusion coefficient. This value is consistent with the extrapolation of bulk data obtained by Pickup and Blum [56] at the same temperature but for larger concentrations of toluene (11\% and larger), which gives $D \sim 10^{-15}-10^{-17} \mathrm{~m}^{2} \mathrm{~s}^{-1}$.

There are several possible explanations for a decrease of the diffusion coefficient as film thickness decreases. Besides those already mentioned in the literature [25], a good candidate is the fact that polymer chains are aligned in the vicinity of interfaces. This has mainly been shown by computer simulations [52, 57-59], and a number of experimental results are consistent with such an interfacial alignment [60-62]. Such an alignment is expected to decrease the mobility of molecules in the direction perpendicular to the surfaces, while the mobility increases in the direction parallel. This has indeed been found in simulations for the mobility of the polymer itself [52]. Fluorescence recovery after photo-bleaching performed on thin PS films, which probes the in-plane diffusion, has shown that the diffusion coefficient of a dye increases (by up to two orders of magnitude) as the film thickness decreases [63, 64]. The alignment of polymer chains by rubbing has also been shown to decrease the diffusion of short chains out of the surface layer (i.e., the diffusion perpendicular to the surfaces decreases) but only by a factor 2 [65]. Our drying experiments, and the absorption experiments of Vogt et al. [23, 25], only probe the diffusion perpendicular to the film surfaces. In view of the above, we indeed expect that the diffusion coefficient determined from these experiments decreases when the film thickness decreases.

The fact that the desorption or absorption rate of small molecules in polymer films is independent of film thickness could, however, be interpreted in a different way than by changes in the diffusivity. This rate could be dominated by a process with a much longer characteristic time than the diffusion process. This is likely to happen for thin films, as the characteristic diffusion time through a film of thickness $h$ varies as $h^{2}$. Therefore, a process with a characteristic time much smaller than the diffusion time through a macroscopic sample (and therefore unnoticeable in the desorption/absorption dynamics of such systems), could become dominant for nanometric systems. In our experiments, the desorption of toluene from the polymer/substrate interface is a good candidate for such a rate-limiting process. At the present state of available data, it is not possible to distinguish between the two types of interpretation presented above.

\section{Conclusions}

GC is able to provide quantitative information on the absolute amount of solvent present in thin polymer films, for thicknesses down to $\sim 10 \mathrm{~nm}$. The thickness dependence of the absolute amount of toluene retained in PS films, after annealing and drying at $115^{\circ} \mathrm{C}$, shows that the solvent is retained at the polymer/substrate interface. As the films get thinner, the relative amount of solvent increases significantly. The desorption rate is essentially independent of the film thickness. This could arise from a strong decrease of the diffusion coefficient of toluene in the polymer as film thickness decreases or from the fact that the desorption process is dominated by another process taking place at much longer time scales than the diffusion of the films.

Acknowledgements We thank the Softlink program of the Dutch Organization for Scientific Research (NWO), Akzo-Nobel and DSM for financial support. We thank D. Long for fruitful discussions.

\section{References}

1. Frank CW, Rao V, Despotopoulou MM, Pease RFW, Hinsberg WD, Miller RD, Rabolt JF (1996) Science 912: 912-915

2. Bornside DE, Macosko CW, Scriven LE (1987) J Imaging Sci Technol 13:122-130 
3. Romdhane IH, Price PE, Miller CA, Benson PT, Wang S (2001) Ind Eng Chem Res 40:3065-3075

4. Richardson H, Sferrazza M, Keddie JL (2003) Eur Phys J E 12:S87-S91

5. Brûlet A, Boué F, Menelle A, Cotton JP (2000) Macromolecules 33:997-1001

6. Reiter G, de Gennes PG (2001) Eur Phys J E 6:25-28

7. Reiter G, Hamieh M, Damman P, Sclavons S, Gabriele S, Vilmin T, Raphael E (2005) Nat Mater 4:754-758

8. Mundra MK, Ellison CJ, Behling RE, Torkelson JM (2006) Polymer 47:7747-7759

9. Croll SG (1979) J Appl Polym Sci 23:847-858

10. Bornside DE, Macosko CW, Scriven LE (1989) J Appl Phys 66:5185-5193

11. Katz A, Ward MD (1996) J Appl Phys 80:4153-4163

12. Bouchard C, Guerrier B, Allain C, Laschitsch A, Saby AC, Johannsmann D (1998) J Appl Polym Sci 69:2235-2246

13. Guerrier B, Bouchard C, Allain C, Benard C (1998) Aiche J 44:791-798

14. de Gennes PG (2002) Eur Phys J E 7:31-34

15. Tsige M, Grest GS (2005) J Phys-Condens Matter 17:S4119_ S4132

16. Saby-Dubreuil AC, Guerrier B, Allain C, Johannsmann D (2001) Polymer 42:1383-1391

17. Pan L, Zhang M, Nakayama Y (1999) J Chem Phys 110:10509

18. Bistac S, Schultz J (1997) Prog Org Coat 31:347-350

19. Grohens Y, Hamon L, Spevacek J, Holl Y (2003) Macromol Symp 203:155-164

20. To T, Wang H, Djurisic AB, Xie MH, Chan WK, Xie Z, Wu C, Tong SY (2004) Thin Solid Films 467:59-65

21. Wu WL, Orts WJ, Majkrzak CJ, Hunston DL (1995) Polym Eng Sci 35:1000-1004

22. Tan NCB, Wu WL, Wallace WE, Davis GT (1998) J Polym Sci B 36:155-162

23. Vogt BD, Soles CL, Lee HJ, Lin EK, Wu WL (2004) Langmuir 20:1453-1458

24. Vogt BD, Soles CL, Jones RL, Wang CY, Lin EK, Wu WL, Satija SK, Goldfarb DL, Angelopoulos M (2004) Langmuir 20:5285-5290

25. Vogt BD, Soles CL, Lee HJ, Lin EK, Wu W (2005) Polymer 46:1635-1642

26. Forrest JA, Dalnoki-Veress K (2001) Adv Colloid Interface Sci 94:167-196

27. Forrest JA, Jones RAL (2000) The glass transition and relaxation dynamics in thin polymer films. In: Karim A, Kumar $\mathrm{S}$ (eds) Polymer surfaces, interfaces and thin films. World Scientific, Singapore, pp 251-294

28. Alcoutlabi M, McKenna GB (2005) J Phys Condens Matter 17:R461-R524

29. Reiter G, Forrest JA (eds) (2002) Special issue on properties of thin polymer films, vol 8 of Eur. Phys. J. E, pp 101-266

30. Shapovalov V, Zaitev VS, Strzhemechny Y, Choudhery F, Zhao W, Schwarz SA, Ge S, Shin K, Sokolov J, Rafailovich MH (2000) Polym Int 49:432-436

31. Kumar N, Gow J (1994) J Chromatogr A 235:235-240

32. Urakami K, Saito Y, Fujiwara Y, Watanabe C, Umemotot K, Godo M, Hashimoto K (2000) Chem Pharm Bull 48: 1894-1897
33. Wallace WE, Tan NCB, Wu WL, Satija S (1998) J Chem Phys 108:3798-3804

34. Reiter G (1994) Macromolecules 27:3046-3052

35. Xie L, Demaggio GB, Frieze WE, Devries J, Gidley DW, Hristov HA, Yee AF (1995) Phys Rev Lett 74:4947-4950

36. Bollinne C, Stone VW, Carlier V, Jonas AM (1999) Macromolecules 32:4719-4724

37. Cao H, Yuan JP, Zhang R, Sundar CS, Jean YC, Suzuki R, Ohdaira T, Nielsen B (1999) Appl Surf Sci 149:116-124

38. Algers J, Suzuki R, Ohdaira T, Maurer FHJ (2004) Polymer 45:4533-4539

39. Stange TG, Mathew R, Evans DF, Hendrickson WA (1992) Langmuir 8:920-926

40. Extrand CW (1993) Langmuir 9:475-480

41. Chow TS (1980) Macromolecules 13:362-364

42. Kent MS, Smith GS, Baker SM, Nyitray A, Browning J, Moore G, Hua DW (1996) J Mater Sci 31:927-937

43. Fowkes FM (1962) J Phys Chem 66:382

44. Van Oss CJ, Chaudhury MK, Good RJ (1988) Chem Rev 88:927-941

45. Jańczuk B, Bialopiotrowicz T (1989) J Colloid Interface Sci 127:189-204

46. Gunde R, Hartland S, Mader R (1995) J Colloid Interface Sci 176:17-30

47. Radelczuk H, Holysz L, Chibowski E (2002) J Adhes Sci Technol 16:1547-1568

48. Peters RD, Yang XM, Kim TK, Sohn BH, Nealey PF (2000) Langmuir 16:4625-4631

49. Wu W (1970) J Phys Chem 74:632-638

50. Fröba AP, Leipertz A (2001) Int J Thermophys 22:41-59

51. Kumar SK, Vacatello M, Yoon DY (1988) J Chem Phys 89:5206-5215

52. Bitsanis I, Hadziioannou G (1990) J Chem Phys 92:3827-3847

53. Tanaka K, Taura A, Ge SR, Takahara A, Kajiyama T (1996) Macromolecules 29:3040-3042

54. Kajiyama T, Tanaka K, Takahara A (1997) Macromolecules $30: 280-285$

55. Crank J (1975) The mathematics of diffusion, 2nd edn. Oxford Univ. Press, Oxford

56. Pickup S, Blum FD (1989) Macromolecules 22:3961-3968

57. Kumar SK, Vacatello M, Yoon DY (1990) Macromolecules 23:2189-2197

58. Baschnagel J, Binder K (1995) Macromolecules 28:6808-6818

59. Mischler C, Baschnagel J, Binder K (2001) Adv Colloid Interface Sci 94:197-227

60. Jones RL, Kumar SK, Ho DL, Briber RM, Russel TP (1999) Nature 386:146-149

61. Jones RL, Kumar SK, Ho DL, Briber RM, Russell TP (2001) Macromolecules 34:559-567

62. Briggman KA, Stephenson JC, Wallace WE, Richter LJ (2001) J Phys Chem B 105:2785-2791

63. Tseng KC, Turro NJ, Durning CJ (2000) Phys Rev E 61:18001811

64. Tseng KC, Turro NJ, Durning CJ (2000) Polymer 41:47514755

65. $\mathrm{Pu} \mathrm{Y,} \mathrm{White} \mathrm{H,} \mathrm{Rafailovich} \mathrm{MH,} \mathrm{Sokolov} \mathrm{J,} \mathrm{Schwarz} \mathrm{SA,}$ Dhinojwala A, Agra DMG, Kumar S (2001) Macromolecules 34:4972-4977 